\title{
Incidência de doenças fúngicas e sanidade de sementes de trigo sob diferentes doses de nitrogênio e aplicação de fungicida *
}

\author{
Maria Aparecida de Souza Tanaka ${ }^{1}$, José Guilherme de Freitas², Priscila Fratin Medina²
}

Instituto Agronômico de Campinas, C. Postal 28, 13001-970, Campinas, SP; 'Centro de Fitossanidade / Fitopatologia, E-mail: matanaka@iac.sp.gov.br; ${ }^{2}$ Centro de Grãos e Fibras; "Parte de Projeto financiado pela FAPESP

Autor para correspondência: Maria Aparecida de Souza Tanaka.

Data de chegada: 22/05/2005. Aceito para publicação em: 16/07/2006

1304

RESUMO

Tanaka, M.A.S; Freitas, J.G.; Medina, P.F. Incidência de doenças fúngicas e sanidade de sementes de trigo sob diferentes doses de nitrogênio e aplicação de fungicida. Summa Phytopathologica, v.34, n.4, p.313-317, 2008

As doenças fúngicas na cultura do trigo são responsáveis pela redução da produtividade, além de aumentar o custo de produção da cultura, em virtude da necessidade de aplicação de fungicidas para o seu controle. Muitos patógenos são transmitidos pelas sementes e desempenham um importante papel na epidemiologia das doenças. O trabalho teve com objetivo verificar o efeito de doses de nitrogênio sobre a severidade de doenças fúngicas e a sanidade de sementes de duas cultivares de trigo, IAC-24 e IAC-60, com e sem aplicação do fungicida propiconazole. Os resultados mostraram efeito polinomial das doses de $\mathrm{N}$ para a severidade da mancha marrom (Bipolaris sorokiniana) nas folhas e linear para as sementes, na ausência do fungicida, para ambas as cultivares.

Palavras-chave adicionais: Triticum aestivum, patologia de sementes, adubação nitrogenada.

\section{ABSTRACT}

Tanaka, M.A.S; Freitas, J.G.; Medina, P.F. Incidence of fungal diseases and wheat seed health, under different nitrogen rates, and fungicide application.Summa Phytopathologica, v.34, n.4, p.313-317, 2008

Many fungal diseases on wheat are responsible for yield loss and besides increasing production cost due to the fungicide application. Many pathogens are seedborne and play an important role in disease epidemiology. The present work was carried out to verify the effect of nitrogen rates and propiconazole application on fungal disease severity and seed health of two wheat cultivars, 'IAC-24' and 'IAC60 '. The results showed a polinomial effect of $\mathrm{N}$ rates on the severity of Bipolaris sorokiniana on leaves and a linear effect on seeds, in the absence of fungicide application, for both cultivars.

Keywords: Triticum aestivum, seed pathology, nitrogen.

As doenças fúngicas na cultura do trigo (Triticum aestivum L.) podem ser responsáveis pela redução da produtividade e aumento do custo de produção, em virtude da necessidade constante de utilização de fungicidas para o seu controle $(9,19,25)$. Além disso, a maioria dos patógenos do trigo é transmitida pelas sementes, que desempenham um importante papel na epidemiologia das doenças $(14,20,21)$.

O grau de severidade das doenças pode ser influenciado por vários fatores e, dentre eles, a nutrição mineral das plantas merece atenção especial $(8,11,13)$.

$\mathrm{O}$ efeito da nutrição mineral sobre as doenças tem despertado cada vez mais o interesse da pesquisa. A sua manipulação pode se constituir em um importante mecanismo de controle de diversas doenças, por afetar a sobrevivência dos patógenos, sua reprodução e desenvolvimento, e o que é mais importante, por alterar os mecanismos fisiológicos e morfológicos de resistência da planta. Em geral, a condição nutricional que permite o máximo desenvolvimento vegetativo, também estimula o crescimento dos patógenos. Dessa maneira, o balanço adequado entre os diversos nutrientes pode minimizar as perdas causadas pelas doenças $(2$, $13,18)$.
Embora o nitrogênio seja o nutriente para o qual a produção de grãos de trigo apresenta maior resposta, as adubações nitrogenadas geralmente tornam as plantas mais suscetíveis às doenças, acarretando perdas que reduzem a produtividade $(4,22)$.

A nutrição mineral das plantas também pode influenciar a qualidade sanitária das sementes, além da produção de grãos. Isto porque os nutrientes são necessários e utilizados na formação e desenvolvimento dos órgãos embrionários, bem como na composição química do material de reserva (6).

Os mecanismos de transmissão dos patógenos para as sementes podem ser influenciados pela resistência e composição química dos tecidos das plantas-mãe $(15,16)$. Nesse contexto, Agarwal \& Sinclair (1) e Carvalho \& Nakagawa (6) esclarecem que a composição química mineral quantitativa das sementes, embora definida geneticamente, pode ser influenciada pelo ambiente em que se desenvolveu a planta-mãe e, logicamente pela fertilidade do solo e pela adubação fornecida.

Conforme já demonstrado por vários autores (1, 4, 6,12), em adição à resistência genética da planta e à virulência / agressividade do patógeno, a nutrição mineral pode condicionar a associação dos patógenos com as sementes e a sua transmissão para as plântulas. 
Uma vez ganhando o interior da semente, os patógenos só colonizam os tecidos se houver disponibilidade dos nutrientes essenciais ao seu desenvolvimento, nutrientes esses fornecidos pela planta-mãe.

Neste trabalho objetivou-se avaliar o efeito de diferentes doses de nitrogênio, em interação com dois genótipos de trigo, sobre a severidade das principais doenças fúngicas, bem como sobre a sanidade das sementes.

\section{MATERIAL E MÉTODOS}

O ensaio foi instalado em campo, no IAC - Centro Experimental de Campinas (solo latossolo roxo mesotrófico, com irrigação por aspersão). O solo foi amostrado e avaliado quanto à fertilidade, em cujos resultados foram baseadas as adubações em $\mathrm{P}$ e $\mathrm{K}$ e micronutrientes (5).

O delineamento estatístico utilizado foi o de blocos ao acaso, em esquema fatorial de parcelas sub-subdivididas, com seis repetições. As parcelas, de 1,2 x 24,0 $\left(28,8 \mathrm{~m}^{2}\right)$ foram constituídas de cinco doses de nitrogênio $(0,30,60,90$ e $120 \mathrm{~kg}$ de N/ha), utilizando uréia como fonte de $\mathrm{N}$. A subparcela foi constituída dos tratamentos com e sem aplicação do fungicida propiconazole, na dose de $125 \mathrm{~g} / \mathrm{ha}$, conforme recomendação para a cultura (18). Os genótipos de trigo IAC-24 e IAC-60 constituíram as subsubparcelas. Cada sub-subparcela foi representada por seis linhas de $3 \mathrm{~m}$ de comprimento, espaçadas $0,20 \mathrm{~m}$ entre si.

A densidade de semeadura foi de 80 sementes por metro linear (1440 sementes por parcela). No sulco de semeadura foi aplicado $1 / 3$ do $\mathrm{N}$ e o restante, no início do estádio de alongamento, 40 dias após a emergência.

As doenças foliares foram avaliadas no estádio de início de maturação fisiológica das plantas. A severidade foi quantificada pela porcentagem de área foliar infectada, amostrando-se 20 folhas bandeira ao acaso por parcela.

Para a ferrugem da folha (Puccinia recondita f.sp. tritici) foi empregada a escala modificada de Cobb, conforme Schramm et al. (23).

As severidades da helmintosporiose ou mancha marrom (Bipolaris sorokiniana) e do oídio (Blumeria graminis f. sp. tritici) foram avaliadas por escala abrangendo 0 a $90 \%$ da área foliar necrosada (18).

As sementes colhidas, em número de 200 por tratamento, foram submetidas à análise de sanidade, utilizando-se o método do papel de filtro ("blotter test") com congelamento, segundo a metodologia recomendada para sementes de trigo (20).

As sementes foram distribuídas, eqüidistantes entre si, sobre três folhas de papel de filtro umedecidas com água destilada esterilizada, contidas em placas de Petri de plástico transparente, de $9 \mathrm{~cm}$ de diâmetro. Em cada placa foram colocadas 25 sementes. A seguir, foram incubadas, em sala com temperatura de $20 \pm 2{ }^{\circ} \mathrm{C}$, em regime intermitente de 12 horas de luz fluorescente branca, de $40 \mathrm{w}$, e 12 horas de escuro, durante 24 horas. A luz foi fornecida por tubos de $120 \mathrm{~cm}$ de comprimento, paralelamente distantes 20 $\mathrm{cm}$ um do outro e $40 \mathrm{~cm}$ acima das placas. Em seguida, as sementes foram submetidas ao congelamento, à temperatura de $-20{ }^{\circ} \mathrm{C}$, durante 24 horas, retornando, após esse período, à sala de incubação, onde permaneceram mais cinco dias.

As avaliações foram realizadas pelo exame das sementes em estereomicroscópio e, quando necessário, a identificação dos fungos foi confirmada pela observação de lâminas em microscópio composto e consulta à literatura pertinente $(3,10,14,20)$.

\section{RESULTADOS E DISCUSSÃO}

Independente das doses de nitrogênio e do tratamento fungicida o rendimento de grãos da cultivar IAC-60 foi quase sempre superior ao da IAC-24 (Tabela 1), confirmando resultados de trabalhos anteriores, realizados por Freitas et al. (8). A maior produtividade foi obtida para a cultivar IAC-60 com a dose de $90 \mathrm{~kg} / \mathrm{ha}$ de nitrogênio e tratamento com fungicida. A correlação entre rendimento de grãos e a severidade da mancha marrom foi de $-36,2 \%$.

Tabela 1. Rendimento de grãos (RG) e severidade da mancha marrom (Bipolaris sorokiniana) (B) na folha "bandeira" no estádio de enchimento de grãos, dentro de cada dose de nitrogênio e de cada genótipo de trigo, sem e com fungicida.

\begin{tabular}{|c|c|c|c|c|c|c|}
\hline \multirow{2}{*}{ Genótipos } & \multirow{2}{*}{ Fungicida } & \multicolumn{5}{|c|}{ Doses de Nitrogênio (kg/ha) } \\
\hline & & 0 & 30 & 60 & 90 & 120 \\
\hline & \multicolumn{6}{|c|}{ Rendimento de grãos (kg/ha) } \\
\hline \multirow[t]{8}{*}{ IAC-24 } & Sem & $2879 a$ & $2811 \mathrm{a}$ & $3326 \mathrm{a}$ & $2819 b$ & $2857 b$ \\
\hline & Com & $2551 \mathrm{a}$ & $3378 \mathrm{a}$ & $3826 \mathrm{a}$ & $3729 a$ & $3677 \mathrm{a}$ \\
\hline & Médias & 2715 & 3095 & 3576 & 3274 & 3267 \\
\hline & & \multicolumn{5}{|c|}{ Mancha marrom (Bipolaris sorokiniana) $\%$} \\
\hline & Sem & $23,4 \mathrm{a}$ & $61,6 \mathrm{a}$ & $76,0 \mathrm{a}$ & $82,7 \mathrm{a}$ & $86,1 \mathrm{a}$ \\
\hline & Com & $2,8 \mathrm{~b}$ & $4,4 \mathrm{~b}$ & $5,3 \mathrm{~b}$ & $6,2 b$ & $6,8 b$ \\
\hline & Médias & 13,1 & 33,0 & 40,1 & 44,5 & 44,5 \\
\hline & & \multicolumn{5}{|c|}{ Rendimento de grãos (kg/ha) } \\
\hline \multirow[t]{7}{*}{ IAC-60 } & Sem & $2555 b$ & $2808 b$ & $3496 b$ & $3288 b$ & $2964 b$ \\
\hline & Com & $3169 a$ & $3659 a$ & $3969 a$ & $4070 \mathrm{a}$ & $3632 a$ \\
\hline & Médias & 2862 & 3234 & 3733 & 3679 & 3297 \\
\hline & & \multicolumn{5}{|c|}{ Mancha marrom (Bipolaris sorokiniana) \% } \\
\hline & Sem & $9,9 \mathrm{a}$ & $15,9 \mathrm{a}$ & $23,2 \mathrm{a}$ & $44,2 \mathrm{a}$ & $66,5 \mathrm{a}$ \\
\hline & Com & $1,9 b$ & $2,2 b$ & $1,8 b$ & $3,0 \mathrm{~b}$ & $3,7 b$ \\
\hline & Médias & 5,9 & 9,1 & 12,5 & 23,6 & 35,1 \\
\hline $\mathrm{CV}(\mathrm{RG})=12,7 \%$ & $\mathrm{CV}(\mathrm{I}$ & $=10,5 \%$ & & & & \\
\hline
\end{tabular}

Médias seguidas pela mesma letra maiúscula ou minúscula, nas colunas, não diferem entre si pelo teste de Tukey a $5 \%$ de probabilidade.

O aumento da dose de nitrogênio promoveu um acréscimo na incidência de mancha marrom nos dois genótipos (Tabela 1), corroborando observações de Bouquet \& Jhonson (4) e Roth et al. (22).

Na Tabela 1 verifica-se, também, que a cultivar IAC-24, além de menor produtividade, foi mais suscetível à mancha marrom. Nesta cultivar, embora a aplicação do fungicida tenha reduzido a severidade da doença em todas as doses de $\mathrm{N}$, apenas a partir da dose de $90 \mathrm{~kg} / \mathrm{ha}$ a aplicação resultou em aumento significativo da produtividade de grãos. Para a IAC-60, no entanto, houve resposta em produtividade para o uso do fungicida e para todas as doses de N.

$\mathrm{Na}$ ausência de fungicida não houve resposta da cultivar IAC-24 ao nitrogênio aplicado, quanto à produtividade (Tabela 2); na IAC-60, por outro lado, a doença ocorreu em menor intensidade, o que permitiu a resposta ao nitrogênio, mesmo sem aplicação do fungicida.

Verifica-se pela Tabela 3 que a severidade dos sintomas de oídio, nas duas cultivares, foi estatisticamente inferior na presença do fungicida, indicando sua eficiência no controle do fungo. 
Tabela 2. Equações de regressão e coeficientes de determinação $\left(R^{2}\right)$ para rendimento de grãos e a severidade de incidência de mancha marrom na folha "bandeira" no estádio de enchimento de grãos.

\begin{tabular}{|c|c|c|c|}
\hline Genótipos & Fungicida & Equação & $\mathbf{R}^{2}$ \\
\hline & & Rendimento d & \\
\hline \multirow[t]{8}{*}{ IAC-24 } & Sem & ns & \\
\hline & Com & $Y=2582+30,6 X-0,18 X^{2}$ & $0,98^{(1)}$ \\
\hline & Médias & $Y=2706+19,1 X-0,12 X^{2}$ & 0,85 \\
\hline & & Bipolaris sor & \\
\hline & Sem & $Y=25,6+1,2 X-0,006 X^{2}$ & 0,98 \\
\hline & Com & $\mathrm{Y}=3,1+0.03 \mathrm{X}$ & 0,97 \\
\hline & Médias & $Y=14,2+0,64 X-0,003 X^{2}$ & 0,98 \\
\hline & & Rendimento $\mathrm{d}$ & \\
\hline \multirow[t]{7}{*}{ IAC- 60} & Sem & $Y=2470+23,8 X-0,16 X^{2}$ & 0,83 \\
\hline & Com & $Y=3243+20,1 X-0,14 X^{2}$ & 0,65 \\
\hline & Médias & $Y=2857+22 X-0,15 X^{2}$ & 0,98 \\
\hline & \multicolumn{3}{|c|}{ Bipolaris sorokiniana } \\
\hline & Sem & $Y=10,3+0,03 X-0,004 X^{2}$ & 0,99 \\
\hline & Com & ns & \\
\hline & Médias & $Y=6,1+0,01 X-0,002 X^{2}$ & 0,99 \\
\hline
\end{tabular}

(1) Significativo ao nível de $5 \%$ pelo teste $t$ $\mathrm{ns}=$ não significativo

Tabela 3. Severidade de oídio (\% de área foliar infectada), dentro de cada dose de $\mathrm{N}$ e cada genótipo de trigo, com e sem fungicida.

\begin{tabular}{|c|c|c|c|c|c|c|c|}
\hline \multirow{2}{*}{ Genótipos } & \multirow{2}{*}{ Fungicida } & \multicolumn{6}{|c|}{ Doses de Nitrogênio (kg/ha) } \\
\hline & & $\mathbf{0}$ & 30 & 60 & 90 & 120 & Média \\
\hline \multirow[t]{2}{*}{ IAC-24 } & Sem & $4,1 \mathrm{a}$ & 9,3 a & $12,1 \mathrm{a}$ & $11,8 \mathrm{a}$ & $10,8 \mathrm{a}$ & $9,6 \mathrm{a}$ \\
\hline & Com & $3,3 \mathrm{~b}$ & $3,3 \mathrm{~b}$ & $2,0 \mathrm{~b}$ & $4,8 \mathrm{~b}$ & $4,8 \mathrm{~b}$ & $3,6 \mathrm{~b}$ \\
\hline \multirow[t]{2}{*}{ IAC-60 } & Sem & $2,5 \mathrm{a}$ & $4,5 \mathrm{a}$ & $5,1 \mathrm{a}$ & $8,4 \mathrm{a}$ & $11,1 \mathrm{a}$ & $6,3 \mathrm{a}$ \\
\hline & Com & $2,1 \mathrm{~b}$ & $2,9 \mathrm{~b}$ & $3,5 \mathrm{~b}$ & $4,9 \mathrm{~b}$ & $3,6 \mathrm{~b}$ & $3,4 \mathrm{~b}$ \\
\hline Média & & & & & & & 5,7 \\
\hline
\end{tabular}

$\mathrm{CV} \%=46,8$

Médias seguidas pela mesma letra, nas colunas e para cada genótipo, não diferem entre si pelo teste de Tukey a $5 \%$ de probabilidade.

Tabela 4. Equações de regressão e coeficientes de determinação $\left(\mathrm{R}^{2}\right)$ para severidade de oídio na folha "bandeira" no estádio de enchimento de grãos.

\begin{tabular}{llll}
\hline Genótipos & Fungicida & Equações & $\mathbf{R}^{2}$ \\
\hline IAC-24 & Sem & $\mathrm{Y}^{(1)}=4,2+0,2 \mathrm{x}-0,001 \mathrm{x}^{2}$ & 0,99 \\
& Com & $\mathrm{ns}$ & \\
IAC-60 & Sem & $\mathrm{Y}=1,6+0,07 \mathrm{x}$ & 0,86 \\
& Com & $\mathrm{ns}$ & \\
& & & 0,94 \\
\hline
\end{tabular}

(1) Significativo ao nível de $5 \%$ pelo teste $\mathrm{t}$

ns = não significativo.
Não houve significância para a regressão polinomial na presença de propiconazole. Por outro lado, sem o fungicida, para a cultivar IAC-24, obteve-se resposta quadrática da manifestação dos sintomas da doença para as doses de N; e para a IAC-60, a resposta foi linear. Em valores médios, no cômputo das duas cultivares, a resposta às doses de $\mathrm{N}$ foi linear (Tabela 4 ).

Pode-se observar, pela Tabela 5, que houve efeito do fungicida sobre a ferrugem da folha apenas nas doses de $90 \mathrm{e}$ $120 \mathrm{~kg} / \mathrm{ha}$ de $\mathrm{N}$. Na Tabela 6 verifica-se que houve resposta linear da intensidade da doença, em função das doses de $\mathrm{N}$, tanto na presença como na ausência do fungicida.

Tabela 5. Severidade de ferrugem da folha (Puccinia recondita), em $\%$ da área foliar infectada, dentro de cada dose de $\mathrm{N}$, e com e sem fungicida.

\begin{tabular}{lllllll}
\hline Fungicida & \multicolumn{7}{c}{ Doses de Nitrogênio (kg/ha) } \\
& 0 & 30 & 60 & 90 & 120 & Média \\
\hline Sem & 4,3 a & 7,0 a & 5,0 a & 13,8 a & 23,8 a & 10,8 a \\
Com & $3,8 \mathrm{a}$ & $2,0 \mathrm{a}$ & $1,0 \mathrm{a}$ & $4,6 \mathrm{~b}$ & $2,5 \mathrm{~b}$ & $2,6 \mathrm{~b}$ \\
\hline Média & \multicolumn{1}{l}{} \\
\hline CV\% = 87,9 \\
Médias seguidas pela mesma letra, nas colunas, não diferem entre si pelo \\
teste de Tukey a 5\% de probabilidade.
\end{tabular}
teste de Tukey a $5 \%$ de probabilidade.

Tabela 6. Regressão polinomial para doses de $\mathrm{N}$ dentro de fungicida, para a severidade de ferrugem da folha (Puccinia recondita).

\begin{tabular}{lll}
\hline Fungicida & Equações & $\mathbf{R}^{2}$ \\
\hline Sem & $\mathrm{Y}^{(1)}=2,2+0,08 \mathrm{x}$ & 0,72 \\
Com & $\mathrm{Y}=1,6+0,15 \mathrm{x}$ & 0,78 \\
\hline
\end{tabular}

(1) Significativo ao nível de $5 \%$ de probabilidade

Os resultados apresentados na Tabela 7 mostram que a utilização do fungicida somente não foi eficiente na redução da incidência de $B$. sorokiniana nas sementes na ausência de N, para os dois genótipos, e nas doses de 30 e $60 \mathrm{~kg} / \mathrm{ha}$, para a cultivar IAC- 60 .

Tabela 7. Sementes com Bipolaris sorokiniana (\%) dentro de cada dose de $\mathrm{N}$ e de cada genótipo de trigo, sem e com fungicida.

\begin{tabular}{llllllll}
\hline Genótipos Fungicida & \multicolumn{7}{c}{ Doses de Nitrogênio (kg/ha) } \\
& & 0 & 30 & 60 & 90 & 120 & Média \\
\hline IAC-24 & Sem & $2,1 \mathrm{a}$ & $4,1 \mathrm{a}$ & $4,4 \mathrm{a}$ & $6,0 \mathrm{a}$ & $7,5 \mathrm{a}$ & $4,8 \mathrm{a}$ \\
& Com & $2,1 \mathrm{a}$ & $2,0 \mathrm{~b}$ & $2,3 \mathrm{~b}$ & $1,2 \mathrm{~b}$ & $1,5 \mathrm{~b}$ & $1,8 \mathrm{~b}$ \\
& & & & & & & \\
IAC-60 & Sem & $1,9 \mathrm{a}$ & $2,4 \mathrm{a}$ & $2,3 \mathrm{a}$ & $3,9 \mathrm{a}$ & $3,1 \mathrm{a}$ & $2,7 \mathrm{a}$ \\
& Com & $1,6 \mathrm{a}$ & $2,1 \mathrm{a}$ & $1,5 \mathrm{a}$ & $1,6 \mathrm{~b}$ & $1,1 \mathrm{~b}$ & $1,6 \mathrm{~b}$ \\
\hline Média & & & & & & 2,7 \\
\hline CV\% $=39,0$ &
\end{tabular}

Médias seguidas pela mesma letra, nas colunas, não diferem entre si pelo teste de Tukey a $5 \%$ de probabilidade.

Houve efeito linear das doses de $\mathrm{N}$ utilizadas sobre a incidência de B. sorokiniana nas sementes, na ausência de propiconazole, para os dois genótipos (Tabela 8).

Apenas nas doses mais altas de $\mathrm{N}$ a incidência de Bipolaris spp. foi significativamente reduzida pela aplicação do fungicida, nas sementes das duas cultivares (Tabela 9). A Tabela 10 mostra que houve efeito das doses de $\mathrm{N}$ sobre a presença de Bipolaris spp. nas sementes dos dois genótipos utilizados, na ausência 
Tabela 8. Equações de regressão e coeficientes de determinação $\left(\mathrm{R}^{2}\right)$ para doses de $\mathrm{N}$ dentro de fungicida e dos genótipos de trigo, para as porcentagens de sementes com Bipolaris sorokiniana.

\begin{tabular}{llcc}
\hline Genótipos & Fungicida & Equações & $\mathbf{R}^{2}$ \\
\hline IAC-24 & Sem & $\mathrm{Y}^{(1)}=2,3+0,04 \mathrm{X}$ & 0,96 \\
& Com & $\mathrm{ns}$ & \\
& & $\mathrm{Y}=1,8+0,01 \mathrm{X}$ & 0,65 \\
IAC-60 & Sem & $\mathrm{ns}$ &
\end{tabular}

Média

$\mathrm{Y}=2,1+0,01 \mathrm{X}$

0,90

(1) Significativo ao nível de $5 \%$ pelo teste

$\mathrm{ns}=$ não significativo

Tabela 9. Sementes com Bipolaris spp. (\%) dentro de cada dose de $\mathrm{N}$ e de cada genótipo de trigo, sem e com fungicida.

\begin{tabular}{|c|c|c|c|c|c|c|c|}
\hline \multicolumn{3}{|c|}{ Genótipos Fungicida } & \multicolumn{5}{|c|}{ Doses de Nitrogênio (kg/ha) } \\
\hline & & 0 & 30 & 60 & 90 & 120 & Média \\
\hline \multirow[t]{2}{*}{ IAC-24 } & Sem & $3,6 \mathrm{a}$ & $3,4 \mathrm{a}$ & $2,0 \mathrm{a}$ & $4,3 \mathrm{a}$ & $3,6 a$ & $3,4 \mathrm{a}$ \\
\hline & Com & $2,0 \mathrm{a}$ & $2,9 \mathrm{a}$ & $1,9 \mathrm{a}$ & $1,8 \mathrm{~b}$ & $2,0 \mathrm{~b}$ & $2,1 b$ \\
\hline \multirow[t]{2}{*}{ IAC-60 } & Sem & $2,9 a$ & $3,0 \mathrm{a}$ & $2,8 \mathrm{a}$ & $3,9 \mathrm{a}$ & $3,0 \mathrm{a}$ & $3,1 \mathrm{a}$ \\
\hline & Com & $1,9 \mathrm{a}$ & $2,0 \mathrm{a}$ & $2,0 \mathrm{a}$ & $1,9 \mathrm{~b}$ & $1,4 \mathrm{~b}$ & $1,8 \mathrm{a}$ \\
\hline Média & & & & & & & 2,6 \\
\hline \multicolumn{3}{|c|}{$\mathrm{VC} \%=50,0$} & & & & \multicolumn{2}{|c|}{$\Delta 5 \%=1,9$} \\
\hline
\end{tabular}

Médias seguidas pela mesma letra, nas colunas, não diferem entre si pelo teste de Tukey a $5 \%$ de probabilidade.

Tabela 10. Regressão polinomial para doses de $\mathrm{N}$ dentro de fungicida e dos genótipos de trigo, para as porcentagens de sementes com Bipolaris spp.

\begin{tabular}{llcl}
\hline Genótipos & Fungicida & Equações & $\mathbf{R}^{2}$ \\
\hline IAC-24 & Sem & $\mathrm{Y}^{(1)}=2,2+0,003 \mathrm{X}$ & 0,25 \\
& Com & ns & \\
& & $\mathrm{Y}=1,9+0,04 \mathrm{X}-0,0002 \mathrm{X}^{2}$ & 0,72 \\
IAC-60 & Sem & ns & \\
& Com & $\mathrm{ns}$ & \\
Geral & & n
\end{tabular}

(1) Significativo ao nível de $5 \%$ pelo teste $\mathrm{t}$ ns = não significativo

do fungicida.

Para Alternaria spp., cuja incidência nas sementes foi acima de $80 \%$, o efeito do tratamento com fungicida foi detectado apenas na dose de $60 \mathrm{~kg} / \mathrm{ha}$ de $\mathrm{N}$ (Tabela 11).

Não se verificou efeito de doses de N, com e sem aplicação do fungicida para as incidências de Fusarium spp., Fusarium graminearum e Phoma spp. nas sementes, que foram baixas, não ultrapassando $2,5,3,4$ e $6,4 \%$, respectivamente.

A severidade das doenças foliares no campo foi relativamente baixa, à exceção da mancha marrom, provavelmente em virtude da temperatura média do ar ter sido superior a $18{ }^{\circ} \mathrm{C}$ durante a condução do experimento, considerada a mais propícia para a infecção por B. sorokiniana (25).

Houve maior incidência de patógenos nas sementes, notadamente $B$. sorokiniana, sob doses crescentes de nitrogênio, o que pode ser atribuído ao efeito desse nutriente sobre o
Tabela 11. Porcentagens de sementes com Alternaria spp. dentro de cada dose de $\mathrm{N}$, com e sem fungicida

\begin{tabular}{lllllll}
\hline Fungicida & \multicolumn{6}{c}{ Doses de Nitrogênio (kg/ha) } \\
\hline & 0 & 30 & 60 & 90 & 120 & Média \\
Sem & $83,9 \mathrm{a}$ & $85,3 \mathrm{a}$ & $84,0 \mathrm{~b}$ & $87,3 \mathrm{a}$ & $86,6 \mathrm{a}$ & $86,0 \mathrm{a}$ \\
Com & $85,9 \mathrm{a}$ & $81,9 \mathrm{a}$ & $88,4 \mathrm{a}$ & $87,1 \mathrm{a}$ & $85,4 \mathrm{a}$ & $85,0 \mathrm{a}$ \\
\hline Média & \multicolumn{7}{c}{} & 85,0 \\
\hline CV\% $=6,0$ & & & & & \\
\hline
\end{tabular}

aumento da predisposição das plantas e das sementes à infecção $(8,12,13)$. Agarwal \& Sinclair (1), Carvalho \& Nakagawa (6), Medeiros et al. (15) e Neergaard (16), alem disso, salientam que a composição química mineral das sementes, embora definida geneticamente, pode ser influenciada pelo ambiente em que se desenvolveu a planta-mãe, bem como pela fertilidade do solo e adubação fornecida.

Mesmo não ocorrendo em níveis elevados nas sementes, deve-se ressaltar a importância do inóculo primário de $B$. sorokiniana na epidemiologia da mancha marrom na cultura do trigo $(19,20,21)$. A redução desse inóculo pela adubação nitrogenada adequada e aplicação de fungicida, conforme evidenciado no trabalho, pode se constituir em relevante ferramenta de controle da doença.

Embora os índices de severidade da mancha marrom tenham sido elevados nas plantas da cultivar IAC-24 sob doses elevadas de $\mathrm{N}$ e na ausência de fungicida (cerca $80 \%$ da área foliar afetada), as incidências de $B$. sorokiniana nas sementes foram relativamente baixas, com máximo de 7,5\% (Tabelas 1 e 7). Esse fato pode ter ocorrido porque a doença afetou a cultura em um estádio avançado do ciclo, sem haver tempo para ocorrer infecção das sementes. Conforme já constatado em outros patossistemas, o nível de incidência do patógeno nas sementes nem sempre é proporcional à severidade de sintomas nas plantas, pois os mecanismos de infecção das sementes podem ser independentes e influenciados pelo ambiente (16).

Conforme verificado no trabalho, doses progressivas de $\mathrm{N}$ podem se correlacionar com aumentos da produtividade, mas tornar as plantas e as sementes mais suscetíveis a patógenos. E, corroborando outros relatos $(15,22,24)$, os resultados mostraram que a adubação da cultura, visando altos rendimentos, nem sempre se traduz na obtenção de sementes de melhor qualidade.

A dose de $60 \mathrm{~kg} / \mathrm{ha}$ de $\mathrm{N}$ foi a que proporcionou o maior retorno em produtividade para a cultura (Tabela 1) e está dentro das doses de 50 e $70 \mathrm{~kg} /$ ha de $\mathrm{N}$, recomendadas para a condução de lavouras de trigo $(5,7,18)$. Os resultados mostraram que esta dose pode também favorecer a severidade de doenças como a mancha marrom e a transmissão de $B$. sorokiniana para as sementes. Entretanto, a aplicação de fungicida apresentou um bom controle, tanto nas plantas como nas sementes, podendo ser considerada uma prática necessária em sistemas de produção de sementes e em lavouras de elevada produtividade. Considerando-se que o nitrogênio é um dos elementos para os quais ocorre maior resposta do trigo em produtividade $(4,22)$, há necessidade de um manejo adequado da adubação nitrogenada, objetivando bons rendimentos sem, no entanto, favorecer a incidência de doenças.

Constatou-se que a pulverização das plantas com o fungicida propiconazole reduziu a incidência de patógenos importantes, como Bipolaris sorokiniana nas plantas e nas sementes, mesmo 
na cultivar mais suscetível e nas doses mais elevadas de nitrogênio, permitindo verificar as perdas. Embora haja necessidade da continuidade desta linha de pesquisa e estudos mais detalhados para confirmação dos resultados, evidenciouse que a utilização, deste ou outro fungicida com eficácia semelhante pode, juntamente com a adubação nitrogenada adequada e genótipos mais resistentes fazer parte de estratégias visando o controle integrado de doenças do trigo.

\section{REFERÊNCIAS BIBLIOGRÁFICAS}

1. Agarwal, V.K.; Sinclair, J.B. Principles of seed pathology. Boca Raton: CRC Press, 1987. 168p.

2. Baligar, V.C.; Duncan, R.R. Crops as enhancers of nutrient use. New York: Academic Press, 1990. 574 p.

3. Barnett, H.L.; Hunter, B.B. Illustrated genera of imperfect fungi. 3.ed. Mineapolis: Burgess, 1972. $241 \mathrm{p}$.

4. Bouquet, D.J.; Johnson, C. Fertilizer effects on yield, grain composition, and foliar disease of double crop soft red winter wheat. Agronomy Journal, Madison, v.79, n.1, p.135-141, 1987.

5. Camargo, C.E.O.; Felício, J.C.; Ferreira Filho, A.W.P.; Freitas, J.G.; Pettinelli Júnior, A. Adubação N, P, K para a cultura do trigo em condição de irrigação por aspersão. Campinas, Instituto Agronômico, 1992. 12p. (Boletim Técnico, 145).

6. Carvalho, N.M.; Nakagawa, J. Sementes: ciência, tecnologia e produção. 3.ed. Campinas: Fundação Cargill, 1988. 424p.

7. Freitas, J.G.; Camargo, C.E.O.; Ferreira Filho, A.W.P.; Castro, J.C. Eficiência e resposta de genótipos de trigo ao nitrogênio. Revista Brasileira de Ciência do Solo, Campinas, v.19, n.1, p. 229-234, 1995.

8. Howard, D.D.; Chambers, A.Y.; Logan, J. Nitrogen and fungicide on yield components and disease severity in wheat. Journal of Production Agriculture. Madison, v.7, n.4, p. 448454, 1994.

9. Jones, D.G.; Clifford, B.C. Cereal diseases. Their pathology and control. 2.ed. New York: John Willey, 1978. 309p.

10. LUZ, W.C. Identificação dos principais fungos das sementes de trigo. Circular Técnica CNPT/EMBRAPA, Passo Fundo, n.1, 1987. 28 p.

11. Lyda, S.D. Alleviating pathogen stress. In: Arkin, G.F.; Taylor, H.M. Modifying the root environment to reduce crop stress. Michigan: American Society of Agriculture and Engineering, 1981, p. 195-214.

12. Malavolta, E. Adubação mineral e sua relação com as doenças das plantas - A visão de um nutricionista de plantas. In: Workshop: a interface solo-raiz (rizosfera) e relações com a disponibilidade de nutrientes, a nutrição e as doenças de plantas, 1998, Piracicaba. Anais. Piracicaba: Potafós/ESALQ/CEA, 1998, p.1-60.

13. Marschner, H. Relationship between mineral nutrition and plant diseases and pests. In: MARSCHNER, H. Mineral nutrition of higher plants. London: Academic Press, 1966. p.369 - 390 .

14. Mathur, S.B.; Cunfer, B.M. Seed-borne diseases and seed health testing of wheat. Copenhagen: Danish Government Institute of Seed Pathology for Developing Countries, 1993. $168 \mathrm{p}$.

15. Medeiros, A.C.S.; Wetzel. M.M.V.S.; Leite, J.C.; Carneiro, J.J.S. Influência do nitrogênio na qualidade fisiológica e sanitária de sementes de cevada. In: Congresso Brasileiro de Sementes, 4., Brasília, 1985. Anais. Brasília: ABRATES, 1985, p.60.

16. Neergaard, P. Seed pathology. 2.ed. London: McMillan, 1979. $1190 \mathrm{p}$.

17. Perrenoud, S. Potassium and plant health. 2.ed. Bern: International Potash Institute, 1990. 363 p.

18. Recomendações da comissão técnica de trigo para 1994. 2.ed. Boletim Técnico CATI , Campinas, n. 216, 1994. 74p.

19. Reis, E.M.; Casa, R.T. Cereais de inverno. In: Vale, F.X.R.; Zambolim, L. (Ed.). Controle de doenças de plantas: grandes culturas. Viçosa: UFV, 1997. v.1, p. 231-287.

20. Reis, E.M.; Casa, R.T. Patologia de sementes de cereais de inverno. Passo Fundo: Aldeia Norte, 1998. 88p.

21. Reis, E.M.; Casa, R.T. Doenças do trigo (Triticum aestivum). In: Kimati, H., Amorim, L., Rezende, J.A.M.; Bergamin Filho, A.; Camargo, L.E.A. Manual de fitopatologia: doenças das grandes culturas. Piracicaba: Ceres, 2005. v.1, p. 631-638.

22. Roth, G.W.; Marshall, H.G.; Hatley, O.E.; Hill Jr., R.R. Effect of management practices on grain yield, test weight, and lodging of soft red winter wheat. Agronomy Journal, Madison, v.76, n.3, p. 379-383, 1987

23. Schramm, W.; Fulco, W.S.; Soares, M.H.G.; Almeida, A.M.P Resistência de cultivares de trigo em experimentação ou cultivo no Rio Grande do Sul, às principais doenças fúngicas. Agronomia Sulriograndense, Porto Alegre, v.10, n.1, p. 31-52, 1974.

24. Tanaka, M.A.S.; Freitas, J.G.; Medina, P.F.; Cantarella, H.; Camargo, C.E.O.; Ferreira Filho, A.W.P.; Felício, J.C. Efeito da adubação nitrogenada sobre a incidência de fungos em sementes de trigo (Triticum aestivum L.). Summa Phytopathologica, Jaboticabal, v.26, n.3, p. 331-335, 2000.

25. Wiese, M.V. Compendium of wheat diseases. St. Paul: A.P.S., 1977,106 p. 